\title{
A construção das políticas de Adaptação às mudanças climáticas: políticas públicas locais nas regiões de Campinas e Limeira.
}

\begin{abstract}
Milena Grandino (IC)
Resumo

A presente pesquisa busca refletir sobre os processos de construção das políticas de adaptação às mudanças climáticas, num cenário crescente de preocupação em relação ao meio ambiente e as necessidades latentes de medidas públicas locais. Esta perspectiva concentra-se em uma exploração teórica dos principais temas que rodeiam esta temática, abordando de forma sistêmica a gestão dos riscos ambientais, a vulnerabilidade e as políticas ambientais no escopo de formação de medidas adaptativas. Em razão disto, o trabalho se desdobra de forma linear para refletir sobre o recorte variado do ambientalismo, das políticas de adaptação, bem como das ações antropogênicas que permeiam as mudanças climáticas há tantos anos.
\end{abstract}

Palavras Chave: Adaptação, Políticas Públicas, Mudanças Climáticas.

\section{Introdução}

Com o ritmo acelerado das mudanças climáticas é necessário que haja processos de manutenção e recuperação dos ecossistemas naturais, diminuindo a vulnerabilidade e mantendo a capacidade de resiliência no território. Dentre estes processos, existem as chamadas "políticas de adaptação", as quais procuram recuperar o sentido de auto-organização do meio ambiente, além de garantir a segurança climática para a população.

A construção destas políticas torna-se essencial para entendermos a gestão dos riscos ambientais difundida na sociedade, nos debates nacionais e internacionais, nas avaliações e análises, relacionando efeitos e fenômenos que potencializam a ação dessas transformações no cotidiano urbano que estamos inseridos.

Para isso, a análise espacial do ambiente possibilita uma compreensão mais ampla dos malefícios gerados pelas mudanças climáticas, tanto em perímetros maiores, quanto menores; porém, a dificuldade e as consequências causadas por tais eventos são mais sentidas e vistas localmente, por isso, surgi o objetivo de analisar 0 andamento nos processos de construção de medidas públicas deste tipo nos municípios, selecionando as cidades de Campinas e Limeira para as análises.

\section{Resultados e Discussão}

A metodologia utilizada nesta pesquisa baseia-se na exposição e reflexão dos conceitos centrais da discussão, isto é, mudanças climáticas, políticas de adaptação, políticas ambientais, escalas e análises políticas, que serão discutidos de forma sequencial em um raciocínio de "linha do tempo".

No que tange aos resultados, as cidades analisadas ainda não possuem concretamente políticas de adaptação às M.C, mas ambas estão desenvolvendo atividades paralelas ao tema, que com mais tempo e estrutura chegarão a desenvolver políticas adaptativas efetivas.

\section{Conclusões}

Esta pesquisa se propôs a mostrar que as mudanças climáticas reportam a urgência e a necessidade de políticas públicas tanto adaptativas, quanto as demais que atuam nestes processos de proteção e prevenção do meu ambiente, contendo cenários de fortes impactos naturais e consequências de difícil reparação.

É claro que ainda há muito que ser feito, mas o que as cidades brasileiras não podem fazer é esperar que catástrofes ocorram para tomar partido em relação a resiliência $e$ as vulnerabilidades do lugar; por isso, o incentivo a interdisciplinaridade com as diversas áreas de estudos deve ser realizado, para estabelecermos um crescimento econômico, social e político sustentável.

\section{Agradecimentos}

Agradeço ao meu orientador, Eduardo José Marandola Jr.; aos meus familiares; e aos amigos que fiz no Laboratório de Geografia dos Riscos e Resiliência. 